\title{
Tuberculoid leprosy on hairy scalp: a case report
}

\author{
A GHORPADE*, C RAMANAN \& P R MANGLANI \\ Department of Dermatology \& Venereology, Main Hospital \& \\ Research Centre, Bhilai Steel Plant, Bhilai, India
}

Accepted for publication 20 January 1988

Summary Involvement of the hairy occipital area of scalp in a patient having tuberculoid leprosy is reported. To the best of our knowledge involvement of hairy scalp by a tuberculoid lesion has not been reported so far.

\section{Introduction}

Scalp is considered to be one of the 'immune zones' in leprosy. The involvement of the scalp in leprosy has been reported, though rarely. In the cases reported so far, the scalp was found to be affected mainly in bacilliferous leprosy and the involvement was mostly on the bald area of the scalp. However, in the present case a tuberculoid lesion was found on the hairy occipital area of the scalp, well inside the hair line.

\section{Case report}

K.R. a 45-year-old Indian male, a worker in the Bhilai Steel Plant, presented to us with the complaints of erythematous skin lesions on both his legs and scalp, of 6-months duration. The lesions were asymptomatic and were gradually increasing in size. There was no family history of similar lesions.

Cutaneous examination revealed a well-defined erythematous, dry, anaesthetic, raised circular plaque about $1^{\prime \prime}$ in diameter with sparse hairs over the occipital area of the hairy scalp (Figure 1). Two similar natured bigger lesions were seen, one on the dorsum of the right foot and the other on the medial aspect of the lower part of the left leg. There was no nerve thickening. The slit-smear examination from the skin lesions did not reveal any acid-fast bacilli. Histopathology from the scalp lesion showed well defined, compact granulomas consisting mainly of lymphocytes and histiocytes with a few Langhans' type of giant cells (Figure 2). These granulomas were located in the upper part of the dermis and at places were eroding the epidermis from below. No acid-fast bacilli were seen in the section.

The patient was put on tablet dapsone, $100 \mathrm{mg}$ daily and capsule rifampicin $600 \mathrm{mg}$ once a month on an empty stomach (supervised). All the lesions responded well after 8 months of combination therapy with dapsone and rif ampicin.

*1-B/Street 13/Hospital Sector, Bhilai (MP), 490006, India 


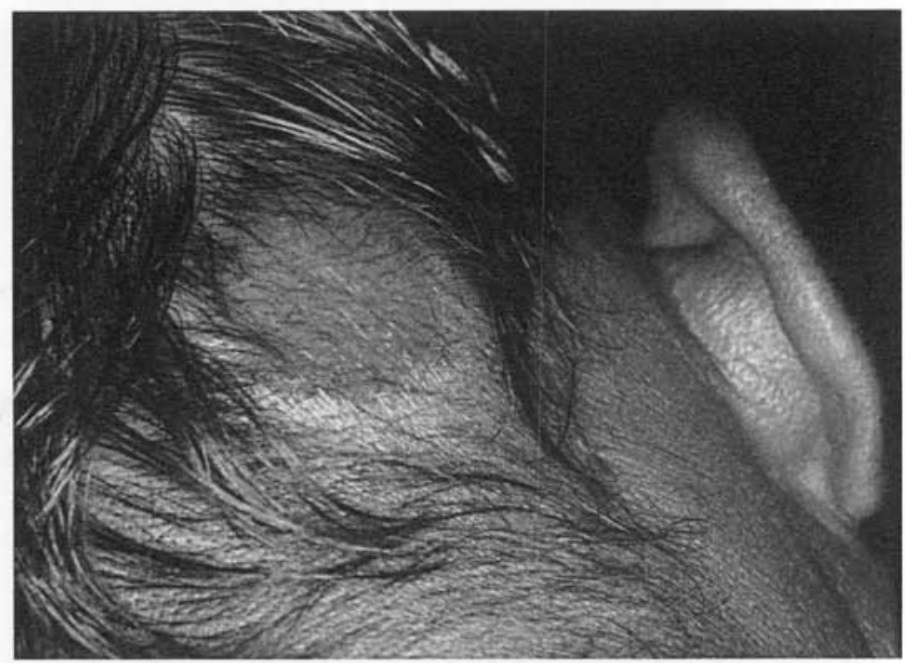

Figure 1. Tuberculoid lesion on occipital area of hairy scalp.

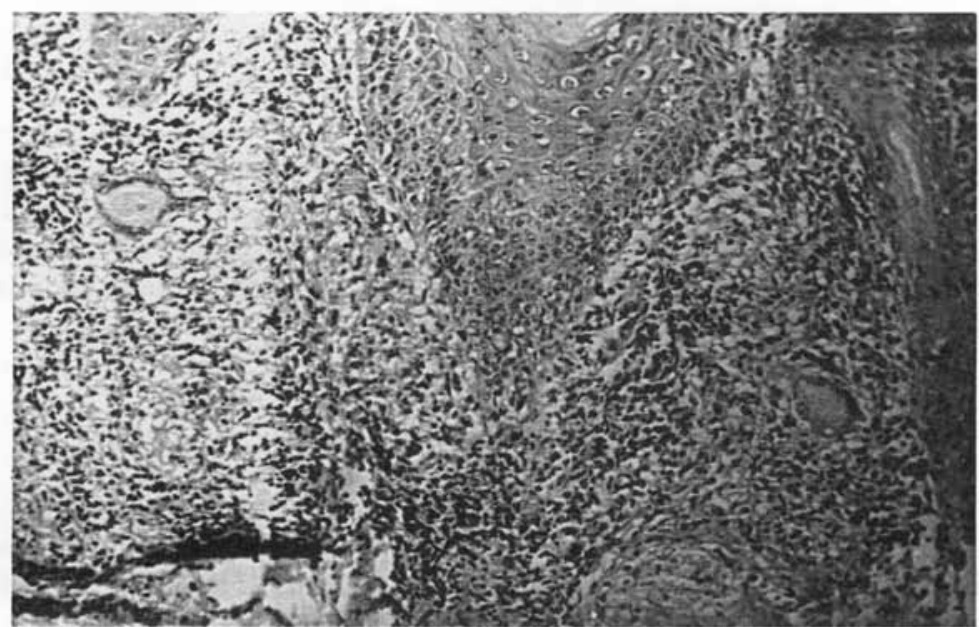

Figure 2. Tuberculoid granuloma with Langhans' giant cells $(H \& E$ original magnification $\times 100)$.

\section{Discussion}

It is known that Mycobacterium leprae has a distinct predilection for the cooler areas of the body. Scalp, which has been shown to have a higher temperature ${ }^{1}$ as compared to that of the forearm, was considered to be one of the 'immune zones' for leprosy. However, in rare instances involvement of the scalp has been described in borderline lepromatous and lepromatous leprosy. Out of the 10 cases of lepromatous leprosy observed by Faget, ${ }^{2} 3$ showed clinical involvement, 2 of them had diffuse infiltration while 1 had a nodular lesion. Involvement of the scalp was also reported ${ }^{3}$ in newly diagnosed cases of lepromatous leprosy. Kaur \& $\mathrm{Kumar}^{4}$ observed acid-f ast bacilli in all the 16 cases of lepromatous leprosy and in 4 cases of borderline leprosy. Bedi $e t$ al $l^{5}$ after a sudy of 20 cases of 
lepromatous leprosy, detected acid-fast bacilli in 2 cases and histopathological changes of leprosy in the scalp of 4 patients. Parikh et al. ${ }^{6}$ observed the involvement of scalp in lepromatous and borderline lepromatous leprosy. Malviya et al..$^{7}$ found lepromatous nodules on a bald area of scalp in a patient of lepromatous leprosy. Parikh et al. ${ }^{8}$ came across a case of borderline tuberculoid leprosy on the scalp of an Indian Brahmin male who had followed the ritual of shaving off his scalp hair throughout his life. In this case, the involvement of scalp was probably due to the equivalent temperature of the shaved and the bald scalp.

However, in the present patient, the tuberculoid lesion was on the hairy occipital area of the scalp. The clinical impression was confirmed after histopathological examination from the scalp lesion. This case suggests that hairy scalp may not always act as an 'immune zone' for leprosy.

\section{References}

1 Anish SA. The relation between surface temperature and dermal invasion in lepromatous leprosy. Int J Lepr, 1971; 39: 848-51.

2 Faget GH. Alopecia leprosa in the United States. Int J Lepr, 1946; 14: 42.

3 Fleury RN, Tolentino MM, Opromolla OVA, Tonello C. Inapparent lepromatous leprosy in the scalp. Abstract in Int J Lepr, 1973; 41:580.

${ }^{4}$ Kaur S, Kumar B. Study of apparently uninvolved skin in leprosy as regards bacillary population at varying sites. Lepr India, 1978; 50: 38-44.

5 Bedi TR, Kumar B, Kaur S. Histopathological study of clinically normal appearing skin in lepromatous leprosy. Lepr India, 1979; 51: 78-80.

6 Parikh AC, D'souza NA, Chulawala R, Ganapati R. Leprosy lesion on the scalp. Lepr India, 1974;46:39-42.

7 Malviya GN, Girdhar BK, Husain S, Ramu G, Lavania RK, Desikan KV. Scalp lesion in a lepromatous patient. Lepr India, 1987; 59: 103-5.

${ }^{8}$ Parikh DA, Oberai C, Ganapati R. Involvement of scalp in leprosy. Lepr India, 1985; 57: 883-6. 
NEWS AND NOTES

\section{St Francis Leprosy Guild, UK}

This agency '. . . collects donations to help missionaries and others in their work among victims of leprosy throughout the world'. Address: 21 The Boltons, London SW10 9SU. Medical adviser: Dr T J Ryan, Consultant Dermatologist, Slade Hospital, Headington, Oxford OX3 7JH, England.

\section{Dermatology and Leprology Research Institute, India}

We are grateful to Mr V Peria Swami, Project Director for the above Institute, Main Road, Anakapalli531 001, Visakhapatnam District, Andhra Pradesh, India, for the following information:

'The Dermatology and Leprology Research Institute took root in November 1986. The building which lodges our Institute was donated by Dr B Narasimha Rao, the Director of this Institute. With funds released by Emmaus Swiss, we renovated the building to make it suitable for our work.

We aim to enthuse private practitioners to treat leprosy patients in their own clinics and disseminate to them sufficient knowledge in diagnosis and treatment, as well as to impart knowledge about modern trends in diagnosis and treatment to undergraduates in medicine. Also, to improve the efficiency of trained nonmedical field workers, they have to be re-oriented in a scientific system of detecting early cases and in techniques to create awareness in the public about the curability of leprosy and the importance of mass cooperation.

Our institute is financially supported by Emmaus Swiss. We do not get any government grants. Our staff includes a qualified doctor, a project officer, senior paramedical worker, accountant, health education worker and physiotherapist.

For teaching purposes we will follow the syllabus prepared by Gandhi Memorial Leprosy Foundation (Wardha, India) which is recognized by the Government of India.'

\section{Intermediate Technology, London, UK}

The Intermediate Technology Development Group (ITDG) was founded in 1965 by the late Dr E F Schumacher, author of Small is Beautiful. ITDG, an independent charity, aims to help people work themselves out of poverty by providing information, advice and assistance on the choice of appropriate technologies. For these technologies to be accessible to those who need them most, they must be relatively small, cheap and simple to use. They must make the best use of readily available local skills and resources, and minimize the demands on scarce and imported resources.

Leaflets about the work of ITDG are available on request. This booklist contains a number of publications that give further information about the Group: IT DG Occasional Paper 2-Appropriate Technology for Rural Development: The IT DG Experience; Appropriate Technology: Technology with a Human Face; and Small is Possible.

Intermediate Technology Publications is the publishing arm of the Intermediate Technology Development Group. UK.

Intermediate Technology Development Group Ltd, 9 King Street, Covent Garden, London WC2E 8HW,

\section{The Heiser Program for Research in Leprosy}

Beginning postdoctoral research fellowships, research grants, and visiting research awards available in amounts up to $\$ 21,000$ per year, plus other allowances. Applicants should have MD, PhD, or equivalent degree. Applications by 1 February 1989, for awards to be activated June to December, 1989. For information, write or telephone: The Heiser Program, 450 East 63 Street, New York, NY 10021, U.S.A. Tel: 212-751-6233. 